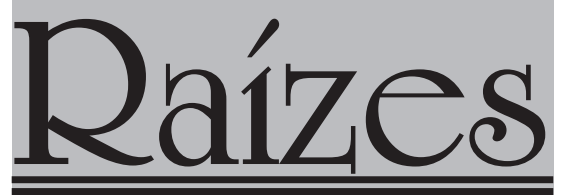

v.33, n.2, jul-dez /2013

\title{
USOS DO CONCEITO DE RESISTÊNCIA COTIDIANA, DE JAMES SCOTT, NA ANÁLISE DO UNIVERSO DAS ORGANIZAÇÕES EMPRESARIAIS: PERSPECTIVAS E PROBLEMATIZAÇÕES
}

$\overline{\text { Darcon Sousa }}$

\section{RESUMO}

Este artigo problematiza a aplicação do conceito de resistência cotidiana - formulado por James C. Scott - ao universo das empresas. Para tanto, definiu-se um percurso teórico para averiguar se a concepção de poder, contemplada na perspectiva de Scott, encontra correspondência no plano da teoria administrativa e na realidade concreta das organizações. Também analisamos dados empíricos coletados em uma organização empresarial da área de serviços em Campina Grande, Paraíba. A premissa do trabalho é a de que conceitos da teoria organizacional dialogam com a perspectiva de Scott, emulando as discussões sobre a aplicação de categorias tais como as de discurso público, discurso oculto e subcultura, manejadas por Scott para formular o conceito de resistência cotidiana nas organizações empresariais.

Palavras-chave: Poder; Conflito; Resistência

\section{USES OF EVERYDAY RESISTANCE CONCEPT, BY JAMES C. SCOTT, IN ANALISING THE UNIVERSE OF BUSINESS ORGANIZATIONS: PERSPECTIVES AND QUESTIONING}

\begin{abstract}
This article investigates the application of the concept of everyday resistance - formulated by James C. Scott - to the business organizations universe. For this, we defined a theoretical path to see if the concept of power, contemplated in the perspective of Scott, finds correspondence in terms of the administrative theory and the reality of organizations. We also analyze empirical data collected from a business company from the services providers sector in Campina Grande, Paraiba (Brazil). The premise of the work conceives the possibility of a dialogue between organizational theories and the Scott perspective, emulating the discussions on the implementation in business organizations of categories such as public speaking, secret speech and subculture, managed by him to formulate the concept of "everyday resistance".
\end{abstract}

Key words: Power; Conflict; Daily Resistance

Doutor em Ciências Sociais. Professor da Universidade Federal de Campina Grande. E-mail: darcon.sousa@ig.com.br.

Raízes, v.33, n.2, jul-dez /2013 
INTRODUÇÃO

James C. Scott desenvolveu o conceito de resistência cotidiana após uma convivência de dois anos entre camponeses da Malásia, ocasião em que pesquisou a reação dos membros da aldeia Sedaka, situada no estado de Kedah, à implantação da "revolução verde", projeto voltado para o aumento da produtividade através de mudanças tecnológicas na colheita do arroz. As consequências dessas mudanças geraram desemprego, aumento das desigualdades e maior dependência dos pequenos agricultores para com os arrendatários de terras, esses últimos elevados à condição de uma nova classe formada por ricos empresários, em contraposição à proletarização e à marginalização que acometiam os primeiros (Scott, 2002; Monsma, 2000). O foco de Scott estava em analisar as práticas e representações cotidianas que, mesmo em pequena escala, prosaicas, fragmentadas e difusas, impõem limites aos detentores do poder e servem como armas para conquistas materiais e simbólicas (Scott, 2002; Monsma, 2000; Menezes, 2002).

As críticas de Monsma (2000) à ênfase de Scott na resistência cotidiana são uma amostra do debate em torno do tema. Esse autor relaciona alguns aspectos que considera problemáticos no conceito de Scott, tais como: a noção voluntarista das ações dos subordinados, a ausência de abordagem sobre a participação dos subordinados na reprodução da dominação e a falta de atenção aos conflitos internos dos grupos subordinados. Além disso, destacase para efeitos dos objetivos deste trabalho, a crítica de que Scott não explica como a resistência cotidiana se aplica à dominação indireta, mediada por mercados e procedimentos burocráticos, típica das instituições impessoais que predominam no mundo atual.

Neste sentido, este artigo pretende investigar as perspectivas de aplicação do conceito de "resistência cotidiana" ao universo das organizações empresarias e identificar aproximações conceituais entre a abordagem de Scott e a teoria organizacional, apresentando algumas concepções de poder presentes nesses dois campos de conhecimento que os aproximam, além de estudos empíricos que indicam a possibilidade do uso do pensamento de Scott no campo das organizações empresariais.

\section{CONCEPÇÕES SOBRE PODER E COM- PREENSÃO DAS RELAÇÕES ENTRE DOMI- NANTES E DOMINADOS}

As análises de James C. Scott privilegiam uma concepção de poder baseada na negociação e na pressão exercida por dominantes e dominados em busca de ganhos e vantagens. Esta visão contrasta com a idéia de que os grupos dominantes teriam controle total sobre os dominados, os quais internalizariam as estruturas formais de poder e seguiriam suas determinações, implicando em um "consentimento normativo" em relação à dominação. Ao invés disso, o poder em Scott é também resultado de barganha e de consenso, face à existência contínua de conflitos, de vigilância recíproca e de representações que o transformam num processo político praticado nas interações cotidianas. (Menezes, 2002; Monsma, 2000; Scott, 1990; Scott, 2002).

Poder, dominação e controle no mundo das corporações, são temas investigados pe- 
las lentes de Karl Marx, Emile Durkheim, Max Weber, Pierre Bourdieu e Michel Foulcault. Esses cientistas sociais desenvolveram conceitos que têm implicações na compreensão do comportamento das organizações, (ver quadro 1), as quais assumem um papel de crescente importância nas sociedades modernas. Merece destaque a aplicação que Bourdieu (2003) faz do conceito de campo como espaço de lutas ao contexto das empresas. Para ele, as decisões que ocorrem no âmbito interno da empresa não dependem de um único ator, mas das relações de forças que compõem o campo de poder em cada firma. Se desvelada a "caixa preta" da empresa, seria possível constatar a "autonomia relativa" dela, não só em relação ao ambiente externo, mas também no que tange aos jogos de poder que se desenvolvem no seu interior. Esses jogos de poder resultam do uso que proprietários, diretores e funcionários fazem de distintos capitais que possuem - incluindo o capital simbólico -, o que lhes permite manejar estratégias de natureza simbólica, destinadas a dissuadir, intimidar e desalentar competidores.

QUADRO 1- A CONTRIBUIÇÃO DOS CIENTISTAS SOCIAIS PARA A COMPREENSÃO DO PODER NAS ORGANIZAÇÕES

\begin{tabular}{|c|c|}
\hline AUTOR & $\begin{array}{c}\text { CONCEITOS RELATIVOS AO PODER } \\
\text { NAS ORGANIZAÇÔES }\end{array}$ \\
\hline $\begin{array}{l}\text { KARL } \\
\text { MARX }\end{array}$ & $\begin{array}{l}\text { As relações de poder nas organizações como } \\
\text { reflexo das relações de poder na sociedade. }\end{array}$ \\
\hline $\begin{array}{c}\text { EMILE } \\
\text { DURKHEIM }\end{array}$ & $\begin{array}{l}\text { Relação entre o conceito de estrutura orga- } \\
\text { nizacional e o exercício do controle através } \\
\text { da estrutura dotada de poder de coerção que } \\
\text { modela a ação, o pensamento e o sentir dos } \\
\text { indivíduos. }\end{array}$ \\
\hline $\begin{array}{l}\text { MAX } \\
\text { WEBER }\end{array}$ & $\begin{array}{l}\text { A concepção de burocracia e de sua hegemo- } \\
\text { nia na sociedade industrial/O papel do po- } \\
\text { der, da autoridade e do controle nas organi- } \\
\text { zações/A dominação exercida sobre os indi- } \\
\text { víduos no processo de trabalho. }\end{array}$ \\
\hline
\end{tabular}

O modelo panóptico utilizado na análise do Michel controle do processo de trabalho/A formaFoUlCAUlT ção dos campos discursivos necessária ao exercício do poder.

O conceito de campo como espaço de lutas

Pierre por posições decididas em função das relaBouRdieu ções/ O poder simbólico como alvo das estratégias de atores que possuem capitais diferentes.

Fonte: Baseado em Carvalho e Vieira, 2007.

No campo da teoria organizacional, a contribuição brasileira de Carvalho e Vieira (2007) para o estudo do poder nas organizações é empreendida a partir do acesso a autores clássicos das ciências sociais. Segundo esses autores, abordagens sociológicas e organizacionais atuais têm enfatizado os aspectos relacionais do poder e a interdependência das partes envolvidas, privilegiando a dinâmica do poder que surge do jogo de interesses divergentes, geradores de situações de conflito e negociação. A estrutura organizacional formal e sua capacidade de internalizar a autoridade perde espaço para análises que apontam para a existência de múltiplos detentores do poder no universo das organizações, transformando-as em arenas políticas.

A noção geral de poder relaciona-se à capacidade ou possibilidade que um indivíduo, um grupo ou instituição tem de agir. No poder da ação estão contidos recursos e estratégias de ordem simbólica explicitadas nas relações humanas e no âmbito dos papéis ocupados, de acordo com as ordenações hierarquicamente estabelecidas. A trama das relações de poder se desenvolve em um jogo de posicionamentos estratégicos dos sujeitos em contextos delimitados, os quais utilizam experiência e negociação para definir os lances escolhidos. As estratégias adotadas geram disputas, resistências, alianças, 
antagonismos e vizinhanças. Uma pesquisa sobre as relações de poder deve incluir: os mecanismos de dominação, os operadores materiais das práticas efetivas, a identificação da maneira como o poder se fragmenta em micro-relações, o mapa da rede relacional da poder e os dispositivos de saber (Noronha, 2003).

Esta compreensão submete as estratégias organizacionais a um processo de negociação permanente em que a racionalização caminha ao lado de formas de comunicação capazes de gerar entendimento e linguagens comuns, num evidente reconhecimento da preponderância dos fatores relacionais e informais presentes nos jogos de poder.

O pensamento estratégico valoriza o menor de todos os atos como parte integrante do processo de negociação. E a negociação é interminável. Seu contrato não se fundamenta em lei ou em norma que vige. A negociação não é propriamente o contrato. Ela é o estado permanente de precariedade de todos os contratos (Noronha, 2003, p.520).

Uma das imagens percebidas por Morgan (1996) sobre as organizações capta a metáfora política para explicar a vida organizacional no dia-a-dia. A política e o jogo político são aspectos importantes das organizações, através dos quais os interesses divergentes são reconciliados de forma negociada. No cenário político da vida organizacional, os conflitos explícitos ou implícitos, se originam nas estruturas organizacionais, nos papéis ou em função de recursos escassos. Por vezes, os conflitos em vez de abertos, repousam sob a superfície do cotidiano. Para resolvê-los, indivíduos e grupos ne- gociam e competem por uma participação no equilíbrio do poder, o que cria uma ordem negociada que impede a predominância de um poder absoluto.

A dimensão política das organizações coloca em relevo o fato de que os objetivos, a estrutura, a tecnologia e outros aspectos formais da organização, não prescindem da consideração aos interesses contraditórios e aos conflitos deles resultantes, assim como do manejo de um poder que nem sempre se estabelece por imposição, mas por consenso. Desse modo, tal percepção implica na desconstrução do mito da "racionalidade organizacional" como condutora da eficiência, da impessoalidade e do alcance de interesses comuns. Nas empresas há diversas racionalidades, nem sempre conciliáveis e permanentemente carregadas de conteúdos políticos. A dimensão política também sugere que as organizações são permeadas por tensões que surgem dos múltiplos interesses nelas existentes, em contraposição à ideia de "sistemas integrados". Além disso, o componente político do comportamento humano se coloca como uma necessidade para lidar com as tensões originárias dos conflitos de interesses, o que significa que as pessoas irão procurar maneiras de obter ganhos sem enfrentamentos diretos contra a estrutura formal estabelecida.

$\mathrm{Na}$ teoria organizacional, sociólogos atestam como a negociação perpassa as hierarquias, estabelecendo processos de pressão e barganha, revelando comportamentos políticos nos membros das organizações empresariais em resposta aos conflitos de interesses.

A elaboração de orçamentos e de padrões de trabalho, a supervisão diária e o controle de trabalho, assim como a busca de oportunida- 
des de carreira, são freqüentemente caracterizados por formas sutis de ganhar sem infringir as regras do jogo. (Morgan, 1996, p.160).

Os comportamentos políticos são previstos por uma concepção "pluralista” do poder organizacional (ver quadro 2), através da qual os interesses, os conflitos e o poder, são melhor compreendidos.

\section{QUAdRO 2 - VISÃO PLURALISTA DO PODER ORGANI- ZACIONAL}

\begin{tabular}{lll}
\hline \multicolumn{1}{c}{ INTERESSES } & \multicolumn{1}{c}{ CONFLITO } & \multicolumn{1}{c}{ PODER } \\
\hline -Ênfase na diver- & -O conflito é uma & -O poder é uma \\
sidade de inte- & característica ine- & variável crucial. \\
resses entre indi- & rente e erradicável & -O poder é o \\
víduos e grupos. & das questões orga- & meio pelo qual \\
-A organização é & nizacionais e acen- & os conflitos são \\
vista como uma & tua seus aspectos & aliviados e resol- \\
coalizão que tem & funcionais poten- & vidos. \\
um interesse pas- & cialmente positi- & -A organização é \\
sageiro nos obje- & vos. & vista como uma \\
tivos formais da & & pluralidade de \\
organização. & & $\begin{array}{l}\text { detentores do } \\
\text { poder que extra- } \\
\end{array}$ \\
& & em seu poder de \\
& & uma pluralidade \\
& & de fontes. \\
\hline
\end{tabular}

Fonte: Baseado em Morgan (1996)

Nesta direção, Collins (2002, p.143), ao apresentar as perspectivas sociológicas da mudança organizacional, destaca entre outras perspectivas teóricas, as implicações da abordagem pluralista para compreender as organizações.

Pluralist as applied to organizations is really a concept borrowed from political theory. In this sense pluralism is a reaction to what might be termed the doctrine of (political sovereignty. The main idea behind pluralism, therefore, is that there is no fi- nal, or abslute authority in society, which can impose its will on the other members of society. Applied to work organizations, the central idea within pluralism is that organizations are composed of various competing interest groups, whose consent and co-operation must be secured if the organization is to function.

Já a configuração do poder elaborada por Mintzberg (apud Martins e Paz, 2000), considera os sistemas de influência (de autoridade, profissional, político e ideológico) e as coalizões de influenciadores internos e externos à organização. A configuração "Instrumento", "Sistema Fechado" e "Autocrática", têm na autoridade o maior influenciador. $\mathrm{Na}$ configuração "Meritocrática" a influência maior é dos especialistas e na "Missionária” a influência é do tipo ideológica. Por fim, na configuração "Arena Política", o fator político é o mais influente. Para encontrar seu rumo ou adaptarse às mudanças impactantes, a organização terá que enfrentar um jogo político de disputas e barganhas, em que as aparências são preservadas, mas os interesses pessoais ganham importância e os jogadores tentam controlar as decisões. Quando aplicaram o modelo para analisar a configuração do poder em uma empresa pública em processo de mudança, Martins e Paz (2000) identificaram a "Arena Política" como configuração preponderante.

No início dos anos oitenta do século passado, segundo Demers (2007), enquanto o modelo transformacional de mudança organizacional - popularizado pela corrente configuracional, cognitiva e por abordagens culturais - ocupava o centro das atenções, um pequeno corpo de trabalhos voltados para a dimensão política da mudança provia um ponto-de-vista alterna- 
tivo que enfatizava o incrementalismo. Depois, uma escola crítica emerge fugindo das tradicionais concepções sobre mudança organizacional. Usando conceitos como dominação e hegemonia na linha de frente, esses autores mais ou menos explicitamente, desafiaram a literatura sobre mudança organizacional que percebia apenas a mudança aparente, ou seja, a mudança que reforçava o sistema de dominação existente. Ainda segundo esse autor, no decorrer da década mencionada à abordagem política vista na literatura gerencial, apresentava a mudança organizacional como um processo dialético em que grupos de interesses divergentes competem mais ou menos abertamente. Enquanto o modelo dominante de mudança transformacional mostrava uma unidade, uma visão consensual das organizações, a abordagem política estava baseada numa imagem pluralista das organizações, onde a luta por poder e os conflitos são parte do processo de mudança.

Neste sentido, há evidências de que em contextos de mudança organizacional, a exemplo do que ocorreu na aldeia de Sedaka estudada por James Scott, a pluralidade de poder se revela através das diversas razões que indivíduos e grupos encontram para resistir às determinações da organização. O receio da perda do emprego e de vantagens econômicas, o medo de que conhecimentos e habilidades se tornem obsoletos, o pouco tempo para se adaptar, o conforto com o status quo e mesmo a defesa do ego, são motivos para a construção de barreiras pelos membros da organização, contra tentativas de impor transformações que possam afetá-los. Por isto é compreensível todo o esforço da teoria organizacional no sentido de dotar os administradores de capacidades especiais para conduzir mudanças (Brocka e Brocka,1994).
Assim, consideramos que a perspectiva política do poder nas organizações torna-se mais visível nos processos de "mudança organizacional", situação em que a negociação interna e a solução de conflitos determinam o êxito dos objetivos planejados, na qual o conceito de poder plural é experimentado, mesmo quando se trata organizações privadas.

Apesar de serem organizações privadas, conforme Motta (2001), nelas o conhecimento, o acesso à informação, o domínio de tecnologia e a habilidade no manejo de símbolos de poder, são fontes de um poder contingencial, descontínuo, localizado e interpretativo, do qual pode resultar obediência, consentimento ou resistência. Ainda que a estrutura formal da organização seja a principal fonte de poder e que imponha limites à liberdade de ação, indivíduos com interesses próprios e grupos de proteção mútua, fazem das tentativas de introdução de novas práticas organizacionais um exercício de negociação contínua, exigindo dos condutores da mudança uma busca maior por consenso em vez da pura expectativa na conformidade.

Para Robbins (2005), a simples escolha de uma alternativa não encerra o processo decisório nas organizações. A implementação das decisões quase sempre ocorre num contexto de ambiguidade, no qual indivíduos e grupos usam suas fontes de poder para agir fora dos papéis formais, de maneira a influenciar a alocação de recursos e a diminuir as arbitrariedades oriundas da natureza subjetiva da maioria dos fatos que ocorrem em uma organização.

Portanto, no campo da teoria organizacional fortemente influenciada pela sociologia das organizações, as concepções de poder estão baseadas na constatação da existência de confli- 
tos e de disputas que se externalizam em pressões recíprocas e demandam a negociação política como forma de assegurar a sobrevivência das organizações. Isto evidencia similaridades com a compreensão de James C. Scott sobre as relações de poder, cujas premissas tornam possível constatar a realidade da resistência cotidiana entre os camponeses, o que no universo das organizações empresariais será discutido na próxima seção.

\section{SINAIS DA RESISTENNCIA COTIDIANA NAS ORGANIZAÇÕES EMPRESARIAIS?}

Quando Scott (2002) descreveu as armas de resistência utilizadas pelos camponeses em sua luta para refrear os ímpetos dos dominantes, escolheu termos como: corpo mole, dissimulação, submissão falsa, saques, incêndios premeditados, ignorância fingida, fofoca, sabotagem, entre outros. O uso dessas armas pelos "relativamente sem poder", prescinde de coordenação, expressa autoajuda individual e foge da confrontação direta com a autoridade. Mesmo assim, estratégias anônimas, não raras, pragmáticas e incorporadas à subcultura camponesa, criam processos de teste e negociação nas relações de poder. Nas palavras de Scott (2002, p.24):

Micro-resistência entre camponeses é qualquer ato de membros da classe que tem como intenção mitigar ou negar obrigações (renda, impostos, deferência) cobradas à essa classe por classes superiores (proprietários de terra, o Estado, proprietários de máquinas, agiotas ou empresas de empréstimo de dinheiro) ou avançar suas próprias reivindicações (terra, assistência, respeito) em relação às classes superiores.
Ao demonstrar a importância da resistência cotidiana camponesa à dominação e ao realçar a contribuição de James C. Scott em relação ao tema, Menezes (2002) confirma o impacto que as práticas cotidianas de resistência podem ter sobre as relações sociais entre dominantes e dominados. Além disso, essa autora destaca os papéis que a cultura e as emoções ocupam nas ações sociais, aspectos desprezados pela concepção de que a consciência de classe é o resultado exclusivo das condições materiais.

No universo empresarial, essas condições materiais se consolidam a partir do final do século XVIII, quando a revolução do carvão e do ferro iniciou a consolidação do modo capitalista de produção, a indústria se transforma no espaço principal da dominação de uma nascente burguesia empresarial sobre a nova classe de trabalhadores assalariados. $\mathrm{O}$ ambiente da fábrica reproduzia as tensões que ocorriam no contexto socioeconômico. As empresas se multiplicavam na mesma proporção da insatisfação dos trabalhadores.

A administração científica, de acordo com Chiavenato (1979), começa a elaborar métodos racionais para que as empresas ganhassem mais produtividade, não sem a resistência dos trabalhadores. Os patrões tentavam ganhar o máximo na hora de fixar o pagamento por peça ou por tarefa, enquanto os trabalhadores reduziam a um terço o ritmo de produção para influenciar os planejadores do trabalho. A partir de então, as abordagens administrativas passaram a estudar os mecanismos compensatórios que pudessem fazer com que o operário permanecesse no chão de fábrica.

Desde então, os operários continuaram a usar de artifícios para controlar o seu próprio 
trabalho, impondo limites à produtividade planejada. Morgan (1996) atestou como eles fazem as máquinas destruírem os produtos quando um ritmo de produção maior é exigido e como sabem simular sobrecarga e cansaço mesmo sob a supervisão rígida. Essas práticas de resistência não significam um desinteresse em permanecer no emprego, mas são formas de restringir o poder dos administradores que, mesmo tendo consciência da sua existência e dos objetivos nelas contidos, sentem-se impotentes e preferem agir como se nada estivesse ocorrendo, talvez por reconhecer o peso da subjetividade no ambiente de trabalho.

A importância dessa subjetividade havia sido objeto de estudo dos pesquisadores da Escola das Relações Humanas, os quais descobriram através de estudos empíricos que os grupos informais constituídos no interior das organizações determinavam as reações à administração (decisões, normas, recompensas e punições). Em vez de fixar-se apenas na racionalidade, na especialização e na autoridade, a Ciência da Administração passaria a dar atenção aos elementos emocionais, não planejados e mesmo irracionais, influenciadores do moral do trabalhador (Chiavenato, 1979).

Ao tratarem dos modelos de administração de recursos humanos, Sainsaulieu e Kirschner (2006), explicam como a busca por eficácia produtiva trouxe à tona a complexidade do fator humano nas organizações, expondo à crítica a racionalização do fator humano. Os esforços contínuos da administração científica para regulamentar a empresa se defrontava constantemente com fatores imprevistos relacionados a comportamentos individuais e coletivos. Má moral, conflitos, comunicação insuficien- te, insubordinação, rotina e falta de iniciativas, arrivistas e críticos, ameaçavam as prescrições técnicas e a organização produtiva. Como resultado, cresceram as preocupações dos gestores de recursos humanos no sentido de atenuar os efeitos de greves, absenteísmo, atrasos, faltas profissionais e outras expressões dos conflitos existentes no interior das organizaçóes. Para a gestão das relações humanas, a face humana relacional e informal das empresas passou a ter peso igual ao da racionalidade dos engenheiros. Descobriu-se que os problemas dos subordinados tinham mais importância do que suas capacidades técnicas e que eles possuíam racionalidades próprias e processos criativos que deveriam ser levados em conta.

De fato, o movimento dos recursos humanos estendeu consideravelmente o campo das preocupações da Administração, mas sem reduzir a dimensão humana a um simples fator de produção. A escola de relações humanas, em seguida a gestão das relações humanas, certamente tem o mérito de modificar o olhar tecnicista das agências de métodos ou mesmo de serviços encarregados de definir os regulamentos da administração. $\mathrm{O}$ poder onipresente da regra $\mathrm{e}$ do método foi transformado por tais ações de políticas de pessoal. Do mesmo modo, o acento colocado sobre as relações, os estilos, os encontros individuais, os grupos humanos reintroduziu uma visão nada idílica, mas mais realista dos meios de trabalho. (Sainsaulieu e Kirschner, 2006, p. 107).

Essa visão realista do trabalho comporta a consideração aos aspectos antes desprezados pelo viés tecnicista. Dentre esses aspectos, a moral dos trabalhadores ganha a atenção de Silva e Vergara (2003) que, preocupados com 
os sentimentos dos indivíduos e com os significados por eles atribuídos às mudanças, ouviram funcionários de empresas em contextos de grandes mudanças, submetendo-lhes uma escala para classificação dos atributos da mudança. O estudo defende que as mudanças têm múltiplas faces e são interpretadas de diferentes maneiras. As resistências aos processos de mudanças, expressas em sentimentos como ansiedade, medo, angústia, raiva e nostalgia, podem ser resultados da incapacidade dos gestores de oferecerem oportunidades para a autoexpressão dos envolvidos, inibindo-os de compartilharem dúvidas, expectativas, concordâncias ou discordâncias, levando-os a desenvolverem mecanismos de defesa. Os processos de mudança seriam pautados em racionalidades que desconsideram os sentimentos dos atores em cena, impedindo-os de se tornarem sujeitos das mudanças. Quando isto acontece, as resistências são inevitáveis.

As resistências podem ser de natureza ativa, nos casos em que o indivíduo usará todas as formas possíveis para impedir que a mudança ocorra através de boicotes, sabotagem, protesto ou enfrentamento. Já as resistências de natureza passiva ocorrem em situações nas quais o indivíduo ignora as mudanças e age como se elas não fossem acontecer (Hernandes e Caldas, 2001). As resistências podem revelar o lado invisível das organizações, relacionado à existência de culturas informais fornecedoras de identidades para indivíduos e grupos, as quais nem sempre estão de acordo com a cultura da organização.

A cultura informal seria algo próximo da idéia de "subcultura", termo utilizado por Scott (2002) para explicar formas de resistên- cia camponesa que, embora possa soar antipático ou aludir a algo inferior, no campo da teoria organizacional encontra similaridades nas análises de Bowditch e Buono (2006). Esses autores acionam a expressão "subcultura" para designar as culturas fragmentadas que existem nas organizações. As variações subculturais implicam em dificuldades para as organizações quando elas pretendem implantar soluções integradoras em toda a empresa. Outro conceito usado pelos mesmos autores e, talvez, ainda mais próximo a idéia de resistência cotidiana, é o conceito de "contraculturas organizacionais". As contraculturas se manifestam no comportamento de indivíduos que rejeitam as normas, os valores, as posições e as realizações da organização, refletindo em muitos casos o desapontamento com o fracasso dos sistemas existentes de apoio cultural e uma resposta que tenta a reconquista do senso de controle desses indivíduos sobre suas próprias vidas.

Scott (1990) introduz ainda no conceito de "resistência cotidiana", o elemento da construção discursiva como instrumento das representações que marcam as relações entre subordinados e os detentores do poder. Essas representações são compreendidas na identificação das diferenças existentes entre o "discurso público" e o "discurso oculto". O discurso público corresponde ao comportamento público dos dominados, o qual busca atender às expectativas dos poderosos através de manifestações lingüísticas, gestuais e práticas que possam demonstrar conformidade em relação ao poder. Do lado dos poderosos, o discurso público consiste na pompa, parafernália, insígnias e outros símbolos acionados em cerimônias públicas para transmitir o estereótipo de poder necessário aos que o detêm. 
Os eventos organizacionais também são carregados de solenidade e de glamour. Rituais são planejados para comunicar a expectativa em relação aos comportamentos, informar os padrões de desempenho, dramatizar os valores, integrar as pessoas (os chamados rituais de passagem) e para preparar as mudanças. No entanto, quando injustiças são percebidas, ou comportamentos reprováveis e antiéticos dos dirigentes são identificados, os rituais são subvertidos através da sabotagem de projetos, desvio de informações, quebra de sigilos e até a reprodução, entre os subordinados, das atitudes condenadas por eles mesmos, gerando um clima de “salve-se quem puder" (Freitas, 2007).

Percebe-se que, fora da cena pública, o discurso oculto elaborado nos espaços particulares de cada uma das partes é constituído por linguagens e práticas que contradizem o discurso público. No caso dos dominados, o discurso oculto é conseqüência do ceticismo, da desconfiança e dos ressentimentos que se traduzem em mecanismos de alívio, inspiram fantasias de vingança e alimentam as resistências.

No município Campina Grande, Paraíba, entrevistamos um funcionário de uma empresa de serviços para averiguarmos a existência de comportamentos e episódios que expressassem formas de resistências no espaço de trabalho da aludida empresa. Em constante processo de modernização tecnológica e de expansão, a empresa tem investido continuamente em métodos de gestão na tentativa de gerar consensos e convergências em relação aos novos objetivos que comumente acompanham processos de mudanças organizacionais. Ao entrevistado foi explicado o conceito de resistência cotidiana formulado por Scott e solicitado que relatasse fatos ocorridos na empresa que tivessem semelhança com esse conceito.

O entrevistado contou que frequentemente funcionários tentam desqualificar gerentes com fofocas e, por vezes, com a divulgação de informações que comprometem a idoneidade desses gerentes. O teor das fofocas e dos comentários depreciativos envolve desde críticas ao modo de vestir-se dos superiores até o deboche em relação às suas decisões. Um grupo de funcionários chegou associar os gerentes e diretores à personagens de um seriado televisivo, criando apelidos para cada um de acordo com os nomes dos protagonistas do seriado, caricaturando a atuação da gestão.

Segundo o relato do entrevistado, nos bastidores da empresa, fora dos encontros formais, funcionários insatisfeitos utilizam "palavrões" para referirem-se aos chefes e costumam censurar colegas que tecem elogios aos chefes nas reuniões. Para esses funcionários, os elogios são instrumentos de bajulação cujo conteúdo deve ser interpretado como o oposto do que é proferido. De igual modo, quando funcionários se envolvem em ocasiões que homenageiam os gerentes (aniversário), o evento vira alvo de "chacotas" por parte de alguns. As reuniões, convocadas quase sempre em horários fora do expediente de trabalho, são motivo de insatisfação para a maioria dos funcionários, havendo quem invente motivos para delas não participar. Viagens, casamentos e outros eventos são utilizados por alguns funcionários para justificar sua ausência. Conforme o entrevistado houve quem anonimamente, denunciasse ao Ministério do Trabalho a ocorrência das reuniões sem correspondente pagamento de horas extras. 
No que se refere ao desempenho dos funcionários, o entrevistado comentou que, em algumas ocasiões, funcionários já extraviaram documentos que evidenciariam erros seus, com consequente perda financeira para a empresa, enquanto outros chegaram a ocultar materiais de clientes, causando desgaste na relação desses com a empresa. Como identificou o entrevistado, alguns funcionários delongam muito tempo no atendimento a alguns clientes com o objetivo de atender o menor número possível de pessoas. As “caixas de sugestões”, utilizadas pela empresa para recolher queixas e opiniões dos clientes, também são utilizadas por funcionários para expressar o que eles não poderiam dizer diretamente aos superiores ou abertamente em reuniões formais, o que se constitui como inferimos, numa modalidade de construção de um discurso oculto.

O discurso oculto como componente da resistência dos subordinados aos planos de mudança dos administradores, salta aos olhos nos resultados da pesquisa de Silva e Vergara (2003), autores que descrevem as falas de trabalhadores expostos a processos de mudança: “dei minha vida por essa organização e agora é isso que recebo"; "essa empresa já foi um bom lugar para trabalhar"; a vida toda nos fizeram vestir a camisa, agora querem que a tiremos"; eles dizem que haverá lugar para todos os que conseguirem se adaptar aos novos tempos, mas como me adaptar se nunca me deram a chance de pensar diferente". Estes discursos se destinam a ameaçar a mudança ou a controlá-la.

Nesta direção, a análise contextual do exercício do poder no âmbito das organizações, feita por Noronha (2003) reconhece os discursos colocados em movimento e as estraté- gias a eles associadas na dinâmica organizacional. Os recursos comunicacionais são acionados contra fenômenos macrossociais, interpessoais, microssociológicos e micropolíticos. Em vez do enfrentamento direto, é a arte de produzir estratégias para o não enfrentamento - dirigidas à superação dos conflitos através da desmontagem permanente da estratégia do inimigo - o segredo do bom jogador que se antecipa aos movimentos do outro e ajusta os papéis de mando e o controle.

As estratégias de controle virão acompanhadas de estratégias de um contracontrole, um contra-ataque, uma contrainterpretação dos sistemas em funcionamento. E eis o jogo do poder novamente visualizado e em funcionamento. As melhores contra-estratégias serão aquelas capazes de causar maior ruído nos processos de comunicação permanente e também maior flutuação nos desempenhos em produtividade (Noronha, 2003, p.520)

Esses ruídos são produzidos fora dos ambientes formais das organizações. São nas "discussões sem registro" que os membros da organização tratam dos aspectos políticos, trocam confidências e identificam afinidades capazes de orientar manobras políticas. Estas articulações de bastidores contaminam os encontros formais, influenciando decisões que ocultam conflitos, intenções e disputas não perceptíveis aos que se limitam a enxergar a formalidade. Nesses encontros, atores políticos lançam mão das mais variadas representações para alcançar seus objetivos (Morgan, 1996).

Observa-se, portanto, que no universo das organizações empresariais os sinais de resis- 
tência são plenamente identificáveis, contradizendo a idéia de que nas organizações formais e impessoais as hierárquicas anulam o poder dos subordinados e neutralizam as variações de comportamento que sejam contrárias às estratégias auto-referentes da cúpula. Alguns tipos de resistência, por seu caráter informal, emocional e simbólica, guardam similaridades com o conceito de resistência de James C. Scott. Boicotes, sabotagens, formações discursivas de resistência advindas dos bastidores das organizações e a enorme carga de subjetividade norteadora das relações intraorganizacionais, indicam que ao lado de um poder aparente que alcança objetivos parciais, coexiste uma organização invisível tal como um iceberg em sua parte submersa, influenciando o curso das ações e determinando as apropriações de recursos materiais e a distribuição de capitais simbólicos.

\section{CONSIDERAÇÕES FINAIS}

Com base nos conceitos e experiências aqui mencionados não se pode, dadas às pretensões deste artigo e considerando os limites sob os quais o mesmo foi elaborado, concluir pela total aplicabilidade dos conceitos de resistência cotidiana de James C. Scott ao universo das organizações empresariais. $\mathrm{O}$ aprofundamento teórico e empírico é sempre indicado quando se pretende estabelecer um diálogo entre conceitos de campos do conhecimento distintos, embora o estudo das relações de poder seja algo comum à Sociologia e à Administração, esta última nutrindo-se também da primeira para a compreensão do tema. Do ponto de vista da pesquisa empírica, talvez o ambiente organizacional apresente maiores dificuldades para a captação da resistência quotidiana, o que poderia ser solucionado apenas com o uso de um procedimento qualitativo do tipo pesquisa -ação, pesquisa participante, ou de entrevistas com informantes confiáveis e privilegiados.

Apesar disso, conforme sustentamos, os sinais aqui identificados trazem à luz formas semelhantes de lidar com a dominação, reproduzidas por trabalhadores no dia-a-dia das intricadas e complexas relações que caracterizam o exercício do poder no universo das organizações, onde a fronteira entre objetividade e subjetividade nem sempre é fácil demarcar.

Portanto, a premissa que inspira este trabalho advoga que as relações entre dominadores e dominados no campo e na cidade, na empresa e na fazenda, na política ou fora dela, preservam pontos em comum, principalmente a evidência de que em qualquer época e espaço, os fatos sociais são também explicados pela via das interações humanas e pelos significados que os sujeitos a elas atribuem e, em muitos casos, mais do que pela ordem formal.

Trabalho recebido em 20/10/2013 Aprovado para publicação em 02/04/2014

\section{REFERÊNCIAS BIBLIOGRÁFICAS}

BOURDIEU, Pierre. Las estructuras sociales de la economia. Barcelona:Editorial Anagrama, 2003.

BOWDITCH, James L.; BUONO, Anthony F. Fundamentos do comportamento organizacional. Rio de Janeiro: LTC, 2006. 
BROCKA, Bruce; BROCKA, M. Suzanne. Gerenciamento da qualidade. São Paulo: Makron Books,1994.

CARVALHO, Cristina Amélia; VIEIRA, Marcelo Milano Falcão. O poder nas organizações. São Paulo: Thompson, 2007.

CHIAVENATO, Idalberto. Teoria geral da administração. São Paulo: McGraw-Hill, 1979.

COLLINS, David. Organizational change: sociological perspectives. New York: Routleedge, 2002.

DEMERS, Christiane. Organizational change thories: a synthesis. California:Sage Publications, Inc., 2007.

FREITAS, Maria Ester de. Cultura organizacional: evolução e crítica. São Paulo: Thompson, 2007.

HERNANDES, José Mauro da Costa; CALDAS, Miguel P.. Resistência à mudança: uma revisão crítica. São Paulo: RAE, v.41, n.2, p.3145, abr-jun-2001.

MARTINS, José Luis Thadeu Pereira; PAZ, Maria das Graças Torres da. Poder e comprometimento em tempo de mudança organizacional: estudo de caso de uma empresa pública de serviços de informática.São Paulo: Revista de Administração de Empresa, v.35,n.4,p.61-71, Out/ Dez,2000.

MENEZES, Marilda A.de. O cotidiano camponês e a sua importância enquanto resistência à dominação: a contribuição de James C. Scott. In: Raízes, v.21, n.01, p.32-44, jan-jun,2002.
MONSMA, Karl. James C. Scott e resistência cotidiana no campo: uma avaliação crítica. In: BIB, n.49, p. $95-121,1^{\circ}$.sem. 2000.

MORGAN, Gareth. Imagens da organização. São Paulo: Atlas,1996.

MOTTA, Paulo Roberto.Transformação organizacional: a teoria e a prática de inovar. Rio de Janeiro: QualityMark, 2001.

NORONHA,Marcio Pizarro. As tramas do poder e o pensamento estratégico.In: BITTENCOURT,Claudia (org). Gestão contemporânea de pessoas. Porto Alegre: ArtMed Ed.Ltda, 2003, p.504-522.

ROBBINS, Stephen P. Comportamento organizacional. São Paulo: Pearson Prentice Hall,2005.

SAINSAULIEU, R.; KIRSCHNER, A.M. Sociologia da empresa: organização, poder, cultura e desenvolvimento no Brasil. Rio de Janeiro: DP\&A Editora, 2006.

SCOTT, James C. Detrás de La história oficial. In: Los dominados y El arte de La resistência. México: Ediciones Era, p.23-40, 1990.

SILVA, José Roberto Gomes da; VERGARA, Sylvia Constant. Sentimentos, subjetividade e supostas resistências à mudança organizacional. São Paulo: ERA,vol. 43, n.3, jul-set-2003. 